\title{
Campylobacter et Helicobacter en pathologie digestive humaine
}

Les Campylobacter et les Helicobacter sont des bactéries à tropisme digestif, qui sont respectivement associées à des diarrhées et à des maladies inflammatoires gastriques. Les Campylobacter sont responsables d'entérites cliniquement très polymorphes, fréquentes et répandues dans le monde entier. La présence de Helicobacter pylori sur la muqueuse gastrique est corrélée à l'existence d'un état inflammatoire pouvant, soit être asymptomatique, soit se manifester par une gastrite antrale de type $B$ ou un ulcère peptique gastro-duodénal. Ces bactéries sont sensibles à de nombreux antibiotiques et aux sels de bismuth. Le rôle de $\boldsymbol{H}$. pylori dans les maladies inflammatoires gastriques est encore discuté. Cette bactérie est très adaptée au milieu gastrique qu'elle colonise, grâce notamment à son uréase exceptionnellement abondante et à des facteurs d'adhérence. Son rôle exact dans la création des lésions de la muqueuse est encore débattu.

\section{Jean-Louis Fauchère Agnès Rosenau}

\section{ADRESSES}

J.L. Fauchère : maîltre de conférence des universilés, biologiste des hôpilaux. CHU NeckerEnfants Malades, laboratoire de bactériologie et hôpital Boucicaut, 78, rue de la Convention, 75730 Paris Cedex 15, France. A. Rosenau : maître de conférence des universilés. CHR de Tours, laboratoire de bactériologie, et hôpital Bretonneau, Paris, es bactéries qui sont aujourd'hui dans le genre Campylobacter (du grec kampulos = incurvé et bacter $=$ bâtonnet) ont été découvertes au début du siècle associées à des maladies du bétail. Au cours des années 1970, ces bactéries ont émergé comme pathogènes chez l'homme et sont, depuis, très étudiées car de nombreuses inconnues persistent encore concernant leur biologie et les propriétés qui déterminent leur pouvoir pathogène [1]. Les Campylobacter ont été récemment répartis dans deux genres bactériens bien distincts : le genre Campylobacter qui comprend 13 espèces distinctes et le genre Helicobacter qui comprend
3 espèces. Ce dernier genre a été individualisé en 1989 pour désigner les "gastric Campylobacter like organisms (GCLO)" retrouvés dans l'estomac au cours des gastrites et des ulcères peptiques. Ce sont des bacilles à Gram négatif, spiralés ou incurvés, mobiles grâce à une ciliature polaire et qui se développent préférentiellement en atmosphère microaérophile, c'est-à-dire sous une teneur réduite en oxygène. Ils semblent particulièrement bien adaptés à la vie sur les muqueuses du tube digestif puisqu'on les retrouve presque toujours soit dans l'intestin ou le colon pour les Campylobacter, soit dans l'estomac pour les Helicobacter. Les Campylobacter sont largement répartis 
chez les animaux ou/et chez l'homme où ils se comportent soit comme des commensaux, soit comme des pathogènes. Les Helicobacter ont au contraire un habitat restreint à l'estomac humain $(H$. pylori) ou à quelques espèces animales ( $H$. felis chez le chat, H. mustelae chez le furet).

Certaines espèces de Campylobacter sont responsables de syndromes diarrhéiques de symptomatologie très polymorphe. Ces entérites à Campylobacter ont une prévalence élevée comparable ou supérieure à celle des gastroentérites à salmonelles ou à E. coli - et sévissent sous tous les climats, chez l'enfant et le jeune adulte. La physiopathologie de ces entérites à Campylobacter est encore mal connue, le type et la gravité de ces maladies dépendent à la fois de facteurs bactériens multiples et du terrain sur lequel ils s'exercent. Le pouvoir pathogène des Helicobacter est encore plus mal connu puisque, pour l'instant, leur rôle direct dans les maladies gastriques auxquelles ils sont associés n'est pas admis par tous.

Cette revue sera centrée sur les espèces de Campylobacter et d'Helicobacter pathogènes pour l'appareil digestif de l'homme et tentera surtout de faire le point des connaissances sur la physiopathologie de ces infections et sur les méthodes diagnostiques et thérapeutiques actuelles.

\section{Étude bactériologique des Campylobacter}

Les Campylobacter sont des bacilles à Gram négatif - de forme incurvée ou hélicoïdale, très mobiles grâce à un cil polaire - , qui, en raison de leur morphologie, ont tout d'abord été assignées au genre Vibrio jusqu'à la reconnaissance de leurs particularités métaboliques. En effet, contrairement aux vibrions, leur métabolisme est aérobie strict et microaérophile. Ceci nécessite des techniques de culture particulières puisque l'air leur est toxique en raison de sa trop forte teneur en oxygène. Grâce aux études de chimiotaxonomie commencées dans les années 1970 [2], ce genre a pu être formellement distingué du genre Vibrio d'après la valeur significativement plus basse du pourcentage des bases $G$ et $C$ de leur $\mathrm{m} / \mathrm{s} n^{\circ} 2$, vol. 7, février 91
ADN (29-30 \% contre 40-52 \% pour les Vibrio) et l'absence de fermentation et d'acidification des sucres. Ce genre, qui est actuellement inclus dans la famille des Spirillaceae et qui est assez proche du genre Wolinella, comprend 13 espèces dont certaines sont des agents entéropathogènes humains reconnus [3].

La classification de ces espèces sur une base morphologique et physiologique est plutôt difficile car les caractères phénotypiques qui permettent de les différencier sont peu nombreux. Les techniques récentes d'hybridation ADN-ADN ont aidé à redéfinir ces espèces. Elles ne montrent pas d'homologies génomiques entre elles à l'exception de $C$. jejuni et $C$. coli, d'une part, et de $C$. fetus et $C$. hyointestinalis, d'autre part. Enfin, les relations phylogénétiques qui lient les différentes espèces du genre Campylobacter entre elles et le genre Campylobacter aux autres genres bactériens n'ont pu être établies que par l'étude des homologies de séquences des molécules d'ARN ribosomal. Ces études ont montré que les Campylobacter forment une nouvelle branche phylogénétique très éloignée de celle des autres bactéries à Gram négatif.

\section{Les infections intestinales à Campylobacter}

Entérites à Campylobacter. Les Campylobacter ont longtemps été considérés comme des pathogènes des animaux. Chez les bovins et les ovins, ils sont responsables d'infections génitales pouvant entraîner des stérilités ou des avortements, d'infections digestives ou d'hépatites chez la volaille et de la dysenterie du bétail, qui a été également décrite chez les chiens et les chats. C'est en 1946 et 1947 qu'ont été rapportés aux ÉtatsUnis et en France les premiers cas de campylobactériose humaine, mais, jusqu'en 1972, une centaine d'observations seulement avaient été publiées. Elles concernaient pour la plupart l'espèce $C$. fetus qui était retrouvée dans le sang de patients généralement porteur d'une maladie sous-jacente. Ce n'est qu'à partir de 1972, lorsqu'on maîtrisa les techniques d'isolement de ces bactéries à partir des selles, qu'ont put mettre en évidence le rôle de $C$. jejuni et de $C$. coli dans les cas humains d'entérite et montrer leur grande fréquence. En effet, les Campylobacter sont actuellement reconnus comme un des agents étiologiques majeurs des diarrhées, que ce soit dans les pays industrialisés ou dans ceux en voie de développement.

La symptomatologie de l'entérite à Campylobacter est extrêmement polymorphe [4], le tableau clinique allant d'une absence de symptôme à une entérocolite grave. Classiquement, l'entérite à Campylobacter atteint surtout les enfants de moins de cinq ans. Elle débute par une phase prodromique de deux jours, avec fièvre élevée et frissons, puis survient la phase digestive caractérisée par des nausées, des vomissements, des douleurs abdominales (souvent périombilicales) et ce tableau peut évoquer une appendicite aiguë. La diarrhée apparaît ensuite rapidement, d'abord aqueuse, elle peut devenir muqueuse, sanglante et purulente, et évoquer une dysenterie. L'ensemble de l'épisode aiguë dure de 8 à 10 jours, mais les malades restent excréteurs de Campylobacter souvent pendant plusieurs semaines ou mois ; environ un quart d'entre eux présenteront des rechutes multiples, souvent limitées à des crises abdominales douloureuses.

A côté de ce tableau, il existe de nombreuses formes cliniques dominées par un ou deux symptômes. Les formes dysentériques fébriles sont plus fréquentes chez l'adulte et dans les pays industrialisés, alors que les diarrhées aqueuses non fébriles et souvent bénignes sont plus fréquentes chez les enfants et dans les pays en développement [5].

L'existence d'une inflammation de la muqueuse intestinale est attestée par la présence d'un exsudat et de cellules inflammatoires dans certaines selles, et par les études endoscopiques et histologiques. Quant elles sont effectuées, les sigmoïdoscopies et rectoscopies pratiquées au cours des entérites à Campylobacter montrent des lésions inflammatoires et hémorragiques diverses, pouvant évoquer une shigellose, une salmonellose, une amibiase ou une colite à Clostridium difficile. Les biopsies rectales montrent une inflammation aiguë et des micro- 
lésions riches en polynucléaires, avec parfois de véritables abcès des cryptes. L'architecture de la muqueuse est peu modifiée et la déplétion en mucus est modeste. Dans quelques cas, des études histologiques ont montré des Campylobacter en situation intraentérocytaires ou dans la sous-muqueuse.

Épidémiologie. Les Campylobacter entéropathogènes ( $C$. jejuni ct $C$. coli, $C$. laridis, mais aussi $C$. fecalis, C. hyointestinalis, C. upsaliensis) sont répandus dans le monde entier. Cependant les circonstances de contamination peuvent varier d'un pays à l'autre, en fonction des habitudes alimentaires, du niveau d'hygiène et du climat. Les Campylobacter sont des commensaux de l'intestin de nombreux animaux sauvages ou domestiques (oiseaux, volailles, bovins, ovins, porcs, chiens, chats). La transmission à l'homme se fait soit par contact direct avec ces animaux ou leurs déjections, soit par consommation d'aliments ou d'eau souillés par ces animaux, soit plus rarement d'homme à homme, notamment au sein des communautés d'enfants ou de jeunes adultes. La contamination se fait par voie orale. Une transmission périnatale de la mère à l'enfant est également possible ; dans certains cas, ces infections ont abouti à la mort du fœtus in utero, mais la plupart du temps elles se manifestent, chez le nouveau-né, par une diarrhée sanglante et fébrile ou par une méningite. Dans les pays développés, l'ingestion d'aliments contaminés semble être le mode le plus fréquent de contamination de l'homme. Les aliments habituellement impliqués sont la viande de volaille mal cuite (barbecues, camping), les aliments crus (lait, salades, viandes crues) et les aliments précuisinés contaminés par des manipulations non hygiéniques (mains ou ustensiles souillés par la volaille) et mal conservés [3, 4].

La contamination par les Campylobacter entéropathogènes concerne le plus souvent des sujets isolés. Les cas véritablement épidémiques représentent moins de $10 \%$ des cas d'entérites à Campylobacter. Parmi ces épidémies, ce sont celles d'origine hydrique qui ont été le plus souvent rap-

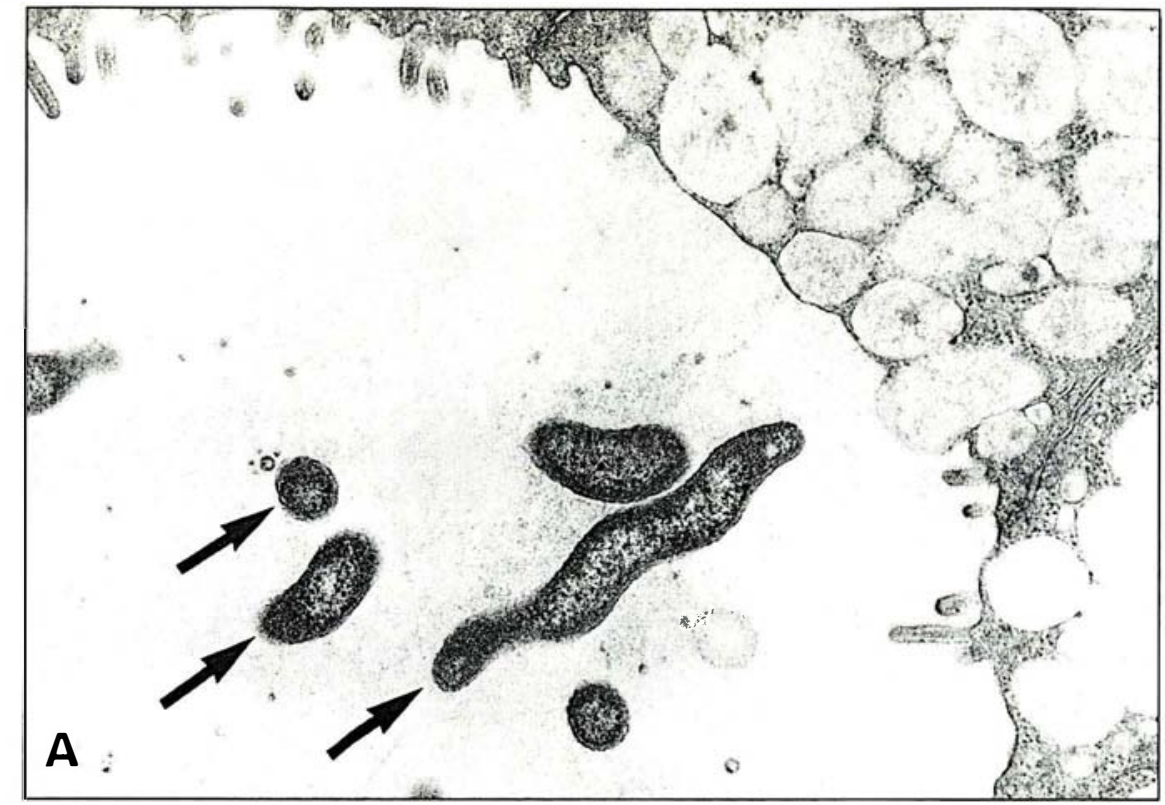

Figure 1. Épithélium colique de souris axéniques infectées depuis deux jours par C. jejuni (microscopie électronique de coupes ultrafines colorées à l'acétate d'uranyle et au citrate de plomb). Les bactéries (flèches) sont observées dans la lumière intestinale (A, ci-dessus), à la surface de la muqueuse, associées au glycocalyx (B page 141) ou incluses dans des vacuoles de phagocytose (C page 141).

consommateurs d'cau contaminéc présentaient une maladic, mais bcaucoup plus étaient porteurs asymptomatiques transitoires. Dans presque tous les cas, il s'agissait de consommation d'eau de surface, contaminée par les animaux et insuffisamment chlorée. Des épidémies par consommation de lait contaminé ou mal stérilisé ont également été rapportées. Ces épidémies surviennent - dans environ la moitié des cas - sur le mode anadémique, c'est-à-dire que la même souche est alors retrouvée chez tous les sujets contaminés et dans la source de contamination.

En Amérique du Nord, les entérites à Campylobacter représentent la deuxième cause bactérienne de maladie diarrhéique après les salmonelles. La fréquence est stable (5 à 6 cas par an pour 100000 habitants) depuis 1980. En Grande-Bretagne, où des relevés épidémiologiques sont pratiqués systématiquement depuis les années 1975, l'incidence des infections à Campylobacter est en constante augmentation depuis 1977 ; C. jejuni et $C$. coli y sont la première cause dc diarrhée bactérienne. En France, comme en Amérique du Nord, la fréquence d'isolement de $C$. jejuni-
C. coli au cours des maladies diarrhéiques cst légèrement inféricure à celle des salmonelles.

La répartition de l'incidence des infections à Campylobacter en fonction de l'âge cst bimodale, avec un premier pic de fréquence avant 1 an et un second entre 15 et 24 ans. Si l'on tient compte de la plus grande fréquence des coprocultures pratiquées chez les enfants, la tranche d'âge la plus exposée est celle des 15-24 ans. $\mathrm{La}$ fréquence maximale des isolcments sc situe pendant les mois d'été, surtout en juin [6].

Dans les pays développés, l'infection par Campylobacter se manif este le plus souvent par une diarrhée sanglante et fébrile (surtout chez les adultes), ou par un portage asymptomatique. Dans les pays en développement, l'incidence de l'infection est maximale avant l'âge de deux ans. Cette infection se manifeste souvent par un portage asymptomatique ou une diarrhée aqueuse non fébrile bénigne [5]. Pourtant, la prévalence des divers marqueurs de virulence (entérotoxine, invasivité) est identique à celle retrouvée dans les pays développés [7] (voir plus loin), et les voyageurs venant des pays industrialisés 

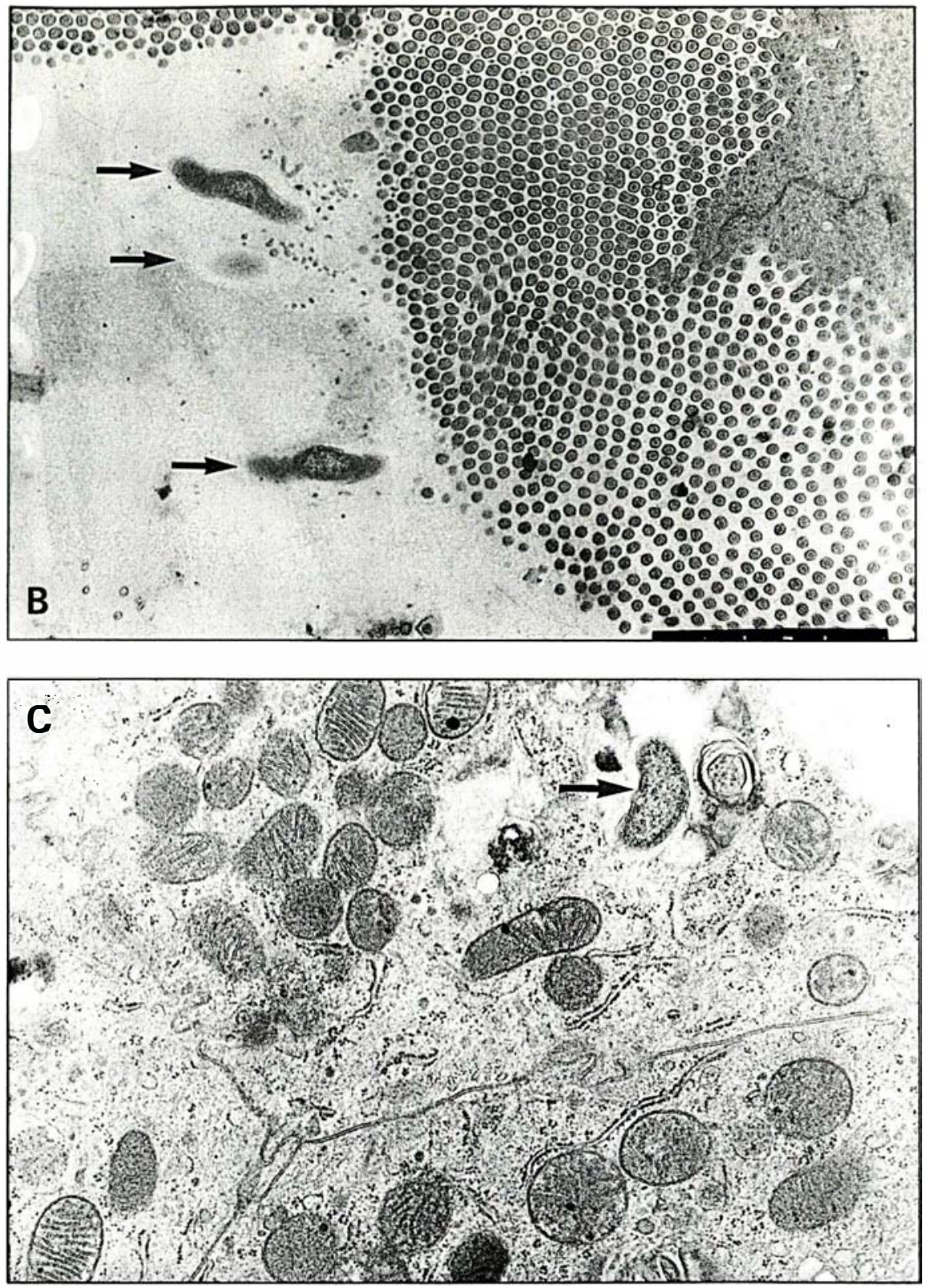

présentent le plus souvent des diarrhées sanglantes et fébriles. On pense qu'une contamination précoce et massive a lieu dans les pays en développement à niveau d'hygiène faible, ce qui a pour conséquence une infection bénigne et l'acquisition d'une immunité durable.

\section{Diagnostic bactériologique des Campylobacter entéropathogènes}

Malgré leur méconnaissance de la part du grand public, les Campylobacter sont retrouvés dans les sclles à une fréquence proche de celle des Salmonella, ce qui justifie leur recherche systématique. C'est principalement dans les selles qu'on recherche ces bactéries, mais les bactériémies sont relativement fréquentes et les hémocultures ne posent alors pas de problème technique particulier. En revanche, la technique de coproculture nécessite des précautions particulières en raison, d'une part, des exigences de culture de ces bactéries et, d'autre part, de l'abondance d'autres bactéries qui peuvent masquer les Campylobacter habituellement peu nombreux et dont la croissance est lente. L'échantillon de selles qui peut être conservé au maximum 12 heures à $4{ }^{\circ} \mathrm{C}$ est observé au microscope à contraste de phase et après coloration de Gram. Dans la plupart des cas, cet examen simple et rapide permet de mettre en évidence les Campylobacter grâce à leur forme et à leur mobilité caractéristiques et permet de rechercher la présence d'hématies et de leucocytes. L'échantillon de selles est également mis en culture sur des milieux renfermant généralement du sang ou du charbon et rendus sélectifs par des antibiotiques inhibant la croissance des autres bactérics. On peut également utiliser des milieux non sélectifs, à condition de filtrer au préalable la selle sur une membrane à pores de $0,65 \mu \mathrm{m}$ de diamètre qui retient la plupart des bactéries, mais qui laisse passer les Campylobacter car ils sont très fins. Cette technique a l'inconvénient de retenir une partie des $C$. jejuni et des $C$. coli, dont le délai de pousse est alors plus long, mais elle permet d'isoler d'autres espèces habituellement inhibées par les milieux sélectifs. La combinaison des deux techniques permet d'obtenir les meilleurs résultats. Les milieux sont incubés pendant au moins 48 heures en atmosphère appauvrie en oxygène et de préférence à $37^{\circ} \mathrm{C}$ pour ne pas inhiber les espèces thermosensibles. Le diagnostic de genre est aisé, il s'agit de fins bacilles incurvés ou spiralés, à Gram négatif, à mobilité caractéristique, à réaction d'oxydase positive et microaérophile. Le diagnostic d'espèce peut généralement être posé à partir de quelques tests simples : production de catalase, sensibilité à l'acide nalidixique et à la céfalotine, croissance à $25^{\circ} \mathrm{C}$ et à $42{ }^{\circ} \mathrm{C}$ et hydrolyse de l'hippurate. Dans certains cas, des tests complémentaires tels que le test d'hydrolyse de l'acétate d'indoxyle récemment décrit, voire des techniques d'hybridation des acides nucléiques seront nécessaires. Enfin, une galerie d'identification pour toutes les espèces de Campylobacter ainsi que des sondes moléculaires pour leur détection directe dans les selles sont en 
cours d'évaluation. Certains marqueurs sérotypiques et biotypiques permettent de subdiviser les espèces $C$. jejuni, $C$. coli et $C$. laridis. Ces techniques sont accessibles aux laboratoires cliniques. La sérotypie par la technique de Lior se fait par agglutination sur lame à l'aide d'immunsérums spécifiques d'antigènes superficiels thermolabiles et permet de différencier 108 sérogroupes dont 15 rassemblent plus de $75 \%$ des souches. Le système de sérotypage de Penner, fondé sur la reconnaissance d'antigènes superficiels par agglutination passive, est plus lourd à mettre en œuvre et moins spécifique. La biotypie repose sur trois tests : l'hydrolyse de l'ADN, l'hydrolyse de l'hippurate et la production rapide d' $\mathrm{H}_{2} \mathrm{~S}$ à partir de composés soufrés minéraux. Elle permet de distinguer deux biotypes de $C$. coli et $C$. laridis et quatre biotypes de $C$. jejuni. Elle est particulièrement utile pour subdiviser les sérotypes les plus fréquents. Pour comparer plus finement les souches, la lysotypie en centre spécialisé permet de distinguer 41 lysotypes en fonction de leur sensibilité à 25 bactériophages.

La sensibilité des Campylobacter aux antibiotiques a fait l'objet de nombreuses études. Tous les Campylobacter sont naturellement résistants à la vancomycine, la bacitracine, la novobiocine, la colymicine, les streptogramines B et le triméthoprime. De plus, $C$. jejuni, $C$. coli et $C$. laridis sont résistants à la céphalotine et $C$. jejuni, $C$. coli, $C$. fetus et $C$. hyointestinalis sont résistants à la rifampicine. La connaissance de ces résistances naturelles a permis l'élaboration des milieux de culture sélectifs et peut être utile à l'identification des différentes espèces. $C$. jejuni et $C$. coli, surtout, sont capables d'acquérir des gènes de résistance présents chez d'autres bactéries sous forme de plasmides ou de transposons, ou de modifier leur génome par des phénomènes de mutation. La fréquence de ces résistances acquises varie selon l'origine géographique des souches, très vraisemblablement en raison de l'utilisation préférentielle des différents antibiotiques selon les régions. Ces résistances rendent indispensables l'étude de la sensibilité in vitro des souches de Campylobacter isolées en cli- nique. Actuellement, $15 \%$ des isolats de $C$. jejuni et $C$. coli sont résistants à l'ampicilline et à l'amoxicilline par production d'une $\beta$ lactamase qui semble être d'origine chromosomique. Les autres $\beta$ lactamines ont peu d'intérêt dans le traitement des infections à Campylobacter. Les aminosides sont généralement très actifs, surtout la gentamicine, mais des gènes de résistance provenant de bactéries à Gram positif ont été observés, notamment des plasmides codant à la fois pour l'inactivation de la kanamycine et de l'amikacine par production d'une phosphotransférase, pour la résistance aux tétracyclines et parfois pour la résistance au chloramphénicol. De plus, des adényltransférases inactivant la streptomycine et la spectinomycine ont été très récemment décrites. Il existe également des plasmides responsables de la résistance aux tétracyclines seules qui sont transférables entre les différentes espèces de Campylobacter. Enfin, certaines souches sont devenues, par des phénomènes de mutation chromosomique, résistantes à l'érythromycine, composé habituellement très actif ainsi qu'aux récentes fluoroquinolones.

Les entérites à Campylobacter guérissent généralement spontanément après quelques jours. Néanmoins, une antibiothérapie peut être indiquée dans les formes sévères ou prolongées. Dans les infections limitées à l'appareil digestif, l'antibiotique de choix est à l'heure actuelle l'érythromycine, qui diminue la durée de la diarrhée et du portage de germes, et, en cas de résistance, une tétracycline. Dans les formes sévères, on recommande l'emploi de la gentamicine par voie injectable.

\section{Physiopathologie des entérites à Campylobacter}

Infections expérimentales. La responsabilité directe des Campylobacter dans les entérites auxquelles ils sont associés est notamment attestée par la réalisation d'infections expérimentales chez des volontaires humains ou chez l'animal. Cependant, les mécanismes physiopathologiques qui conduisent à la maladie sont encore loin d'être élucidés malgré les recherches intenses menées dans de nombreux pays depuis une quinzaine d'années [8].

Plusieurs expériences, chez des volontaires ayant ingéré une suspension bactérienne, ont démontré que la dose minimale induisant une maladie était très variable d'un sujet à l'autre et d'une souche à l'autre. Cette dose minimale variait selon les études entre 500 et $10^{6}$ bactéries ; la colonisation de l'intestin était dosedépendante, mais la gravité des signes cliniques n'était pas reliée clairement à la dose ingérée et plusieurs types de manifestations cliniques, selon la souche infectante, étaient observés [9].

L'utilisation d'animaux courants de laboratoire pour réaliser un modèle animal capable de reproduire l'entérite humaine à Campylobacter s'est avérée difficile, les modèles utilisés pour les autres bactéries entéropathogènes s'étant révélés peu performants. Les animaux les plus sensibles semblent être les nouveau-nés. Les poussins ou les souriceaux développent des maladies habituellement graves, avec diarrhée sévère, bactériémie et mortalité non négligeable; cependant, les résultats obtenus avec ces modèles semblent peu reproductibles d'un laboratoire à l'autre. Les modèles utilisant les petits animaux adultes de laboratoire, comme les souris ou les hamsters, n'aboutissent qu'à une colonisation transitoire de l'intestin sans signes cliniques, mais avec une bactériémie précoce et fugace.

Les modèles utilisant les animaux gnotoxéniques (c'est-à-dire dont la flore digestive est contrôlée) semblent beaucoup plus intéressants. Dans ces modèles, le contrôle de la flore commensale d'accompagnement permet d'étudier son rôle dans l'implantation intestinale des Campylobacter, qui colonisent facilement et durablement l'intestin d'animaux axéniques (germfree) ou à flore commensale simplifiée (animaux gnotoxéniques ou traités par des antibiotiques). On a pu ainsi démontrer l'effet antagoniste de la flore commensale sur l'implantation des Campylobacter, quantifier la colonisation des muqueuses intestinales de la souris et étudier la translocation des Campylobacter, c'est-à-dire leur passage de l'intestin vers les autres organes [10]. Grâce à ce type 
de modèle, le rôle du mucus dans la colonisation de l'intestin a pu également être étudié.

L'infection de lapins adultes par le procédé de l'anse intestinale transitoirement ligaturée (procédé RITARD : removable intestinal tie-adult rabbit diarrhoea) donne une maladie reproductible, mais dont les symptômes sont plus accentués que ceux de la maladie humaine. Les bactéries sont injectées dans une anse iléale préalablement ligaturée, puis le transit est rétabli quatre heures après. Dans ces conditions, les lapins ont - en 24 à $96 \mathrm{~h}$ - une diarrhée sanglante, accompagnée de lésions inflammatoires de la muqueuse colique et d'une septicémie, mortelle dans $50 \%$ des cas. Les animaux survivants développent une réponse immunitaire protectrice [11]. Ce modèle est malheureusement trop lourd pour permettre d'étudier la virulence d'un grand nombre de souches, mais il est utile pour l'étude des phénomènes pathologiques et de la réponse immunitaire à l'infection.

Ces modèles ont démontré que l'infection per os par C. jejuni est suivie de la colonisation des muqueuses surtout iléales et coliques. L'adaptation des Campylobacter au milieu visqueux que constitue le mucus favorise son implantation, alors que la flore commensale tend à s'y opposer. La microscopie électronique montre que la colonisation par certaines souches s'accompagne d'une association intime des bactéries aux microvillosités entérocytaires et d'une internalisation de quelques bactéries (figure 1 p. 141). Dans certains modèles, des lésions histologiques inflammatoires sont notées. Les bactéries semblent coloniser préférentiellement les structures lymphoïdes de l'intestin, en particulier les ganglions mésentériques et les cellules $M$ des plaques de Peyer [12]. Ce phénomène serait à l'origine de la translocation des Campylobacter depuis l'intestin vers la lymphe, le sang et les organes [10]. Une bactériémie précoce et fugace est observée, qui évolue en véritable septicémie dans certains modèles ; cependant, la plupart des souches sont très sensibles à l'activité bactéricide du plasma. Ces phénomènes s'accompagnent de la production d'anticorps protecteurs vis-à-vis d'une infection homologue ultérieure.

$m / s n^{\circ} 2$, vol. 7, féurier 91

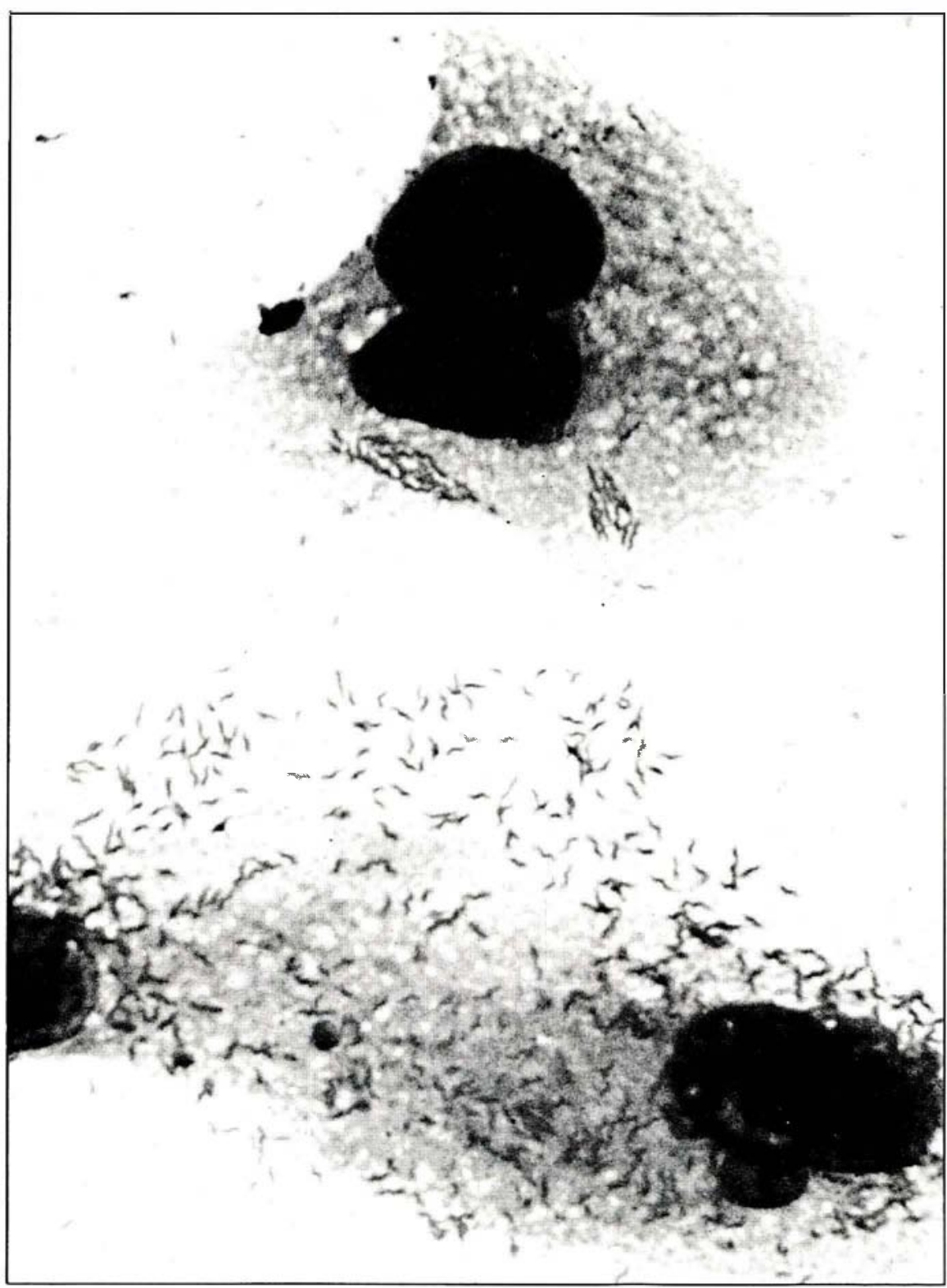

Figure 2. Aspects microscopiques de l'association in vitro de C. jejuni avec des cellules HeLa. Les bactéries apparaissent soit dispersées sur tout le cytoplasme, soit groupées en paquet. Ces deux types d'association sont observés successivement au cours du temps lors d'un même test.

Facteurs bactériens de virulence. La colonisation de la muqueuse intestinale semble favorisée en partie par la mobilité des bactéries et par des propriétés chimiotactiques. Des variants immobiles aflagellés utilisés pour infecter des lapins n'ont pas été retrouvés dans les selles de ces animaux où seuls les variants révertants mobiles étaient isolés [8]. Un grand nombre de composés semblent doué d'un chimiotactisme positif pour C. jejuni, en particulier des sucres (L- fucose), des acides aminés (cystéine, glutamate, L-sérine, aspartate) ou des acides organiques (fumarate, citrate, malate, $\alpha$-cétoglutarate). Par rapport à la flore commensale, $C$. jejuni semble posséder un avantage sélectif dans le milieu visqueux constitué par le mucus du fond des cryptes où il reste mobile. Cette affinité pour le mucus est supprimée pour les variants immobiles ou en présence d'IgA immobilisantes. En microscopie électronique, les Campylobacter retrouvés 


\section{RÉFÉRENCES}

1. Penner JL. The genus Campylobacter: a decade of progress. Clin Microb Rev 1988 ; $1: 157-72$.

2. Veron M, Chatelain R. Taxonomic study of the genus Campylobacter Sebald and Veron and designation of the neotype strain of the species Campylobacter fetus (Smith and Taylor) Sebald and Veron. Int J Syst Bact $1973 ; 23: 122-34$

3. Véron M, Fauchère JL. Campylobacter. In : Leminor L, Véron M, eds. Bactériologie médicale $\left(2^{e} e ́ d\right)$. Paris : Flammarion, 1989 : 694-722.

4. Butzler JP. Campylobacter Infection in Man Animals. Boca Raton: CRC Press, 1984.

5. Cover TL, Blaser MJ. The pathobiology of Campylobacter infections in humans. Am Rev Med 1989 ; 40 : 269-85.

6. Skirrow MB. A demographic survey of Campylobacter, Salmonella and Shigella infections in England. Epidem Inf 1987; 99 : 647-57.

7. Fendri C, Rosenau A, Moyen EN, Fauchc̀re JL. Prevalence of virulence markers of enteric Campylobacter, in France and Tunisia. Res Microbiol 1991 (sous presse)

8. Walker RI, Caldwell MB, Lee EC, Guerry P, Trust TJ, Ruiz-Palacios GM Pathophysiology of Campylobacter enteritis. Microbiol Rev 1986 ; 50 : 81-94

9. Black RE, Levine MM, Clements ML, et al. Experimental Campylobacter jejuni infection in humans. J Infect Dis $1988 ; 157$ : 472-9.

10. Fauchère JL, Veron $M$, LellouchTubiana A, Pfister A. Experimental infection of gnotobiotic mice with Campylobacter jejuni : colonization of intestine and spread to lymphoid and reticulo-endothelial organs. J Med Microbiol 1985; 20 : 215-24.

11. Caldwell MB, Walker RI, Stewart SD, Rogers JE. Simple adult rabbit model for Campylobacter jejuni enteritis. Infect Immun 1983 ; 42 : 1176-82.

12. Walker RI, Schmauder-Chock EA, Parker JL, Burr D. Selective association and transport of Campylobacter jejuni throught $\mathrm{M}$ cells of rabbit Peyer's patches. Can J Micro- dans le mucus des cryptes sont mobiles et ne semblent pas fixés aux entérocytes.

Si toutes les souches semblent capables de coloniser l'intestin, l'association des bactéries aux cellules épithéliales in vitro est significativement plus fréquente dans le cas de souches isolées de patients présentant une diarrhée fébrile et sanglante [13]. Dans ce modèle, les bactéries fixées aux cellules restent mobiles comme cela a été montré par microcinématographie. Au cours du temps les bactéries, d'abord fixées de façon dispersée subissent, une redistribution à la surface de la cellule et apparaissent ensuite regroupées (figure 2, page précédente). L'adhérence des Campylobacter aux cellules épithéliales est suivie de l'internalisation de nombreuses bactéries dans les cellules hôtes (figure 3). Ce phénomène pourrait être le fait de l'activité phagocytaire de cellules hôtes qui ne sont pas des phagocytes professionnels [13]. Cependant ces bactéries ne sc multiplient plus dans les cellules et sont éliminées en 12 heures environ, contrairement aux bactéries invasives comme les shigelles ou certains $E$. coli qui se multiplient dans la cellule hôte et la détruisent.

La nature des structures bactériennes et des récepteurs cellulaires impliqués dans l'adhérence des Campylobacter entéropathogènes est encore mal connue. Ces bactéries sont dépourvues de pili; les structures bactériennes pouvant jouer le rôle d'adhésine sont des constituants de la membrane externe comme la flagelline, le LPS (lipopolysaccharide) ou des protéines de la membrane externe. Un groupe de protéines de 26 à $30 \mathrm{kDa}$ a été identifié dans notre laboratoire comme ayant des propriétés d'adhérence spécifiques aux cellules épithéliales (figure 4, p. 146) [14]. Ces protéines, présentes chez toutes les souches, ne sont adhérentes que chez les souches pathogènes et pourraient en fait assurer la fixation de la bactérie. Nous poursuivons actuellement la purification et l'étude de la structure de ces protéines qui pourraient être utilisées comme marqueurs de pathogénicité ou comme protéines vaccinantes, car elles sont très immunogènes et induisent la synthèse d'anticorps protecteurs [14].

Plusieurs auteurs ont montré que cer- taines souches de Campylobacter entéropathogènes produisaient une entérotoxine présentant des analogies structurales et fonctionnnelles avec la toxine LT de $E$. coli et avec la toxine cholérique. Les surnageants de cultures de $C$. jejuni sont ainsi capables de dilater une anse intestinale ligaturée de rat ou de lapin. Ces surnageants présentent également un effet cytotoxique sur les cultures de cellules $\mathrm{CHO}$ et $\mathrm{Y} 1$ dont ils modifient la morphologie et dans lesquelles la teneur en AMPc augmente. Ces activités sont inhibées par des sérums antitoxinc cholérique et anti-toxine LT de $E$. coli, ou par des anticorps spécifiques retrouvés chez les patients infectés. L'entérotoxine de $C$. jejuni serait une protéine de 60 à $80 \mathrm{kDa}$, thermolabile et stable entre $\mathrm{pH} 2$ et $\mathrm{pH} 8$. Cette toxine semble se fixer spécifiquement sur le ganglioside GM1 des membranes cellulaires. Cependant cette entérotoxine n'est produite que dans des conditions de culture difficiles à reproduire. De plus, une sonde moléculaire spécifique du gène de l'entérotoxine du choléra n'a pas permis de mettre ce gène en évidence dans les souches de Campylobacter censées produire cette entérotoxine. Le phénotype entérotoxinogène a pu néanmoins être transféré par conjugaison plasmidique vers une souche de $C$. fetus non toxinogène. Les transconjuguants de $C$. fetus devenaient alors capables de retransférer le caractère tox ${ }^{+}$vers des souches de $C$. jejuni. On admet actuellement que la production de toxine est codée par un gène chromosomique qui pourrait être mobilisé par certains plasmides, mais l'existence même de cette toxine est encore contestée.

Une activité cytotoxique, thermolabile et sensible à la trypsine, a été également démontrée in vitro dans les surnageants de culture de $C$. jejuni. Cette toxine n'est pas neutralisée par un sérum anti-SLT1 de Shigella dysenteriae ni par un sérum anti-toxine de C. difficile.

Le rôle exact de ces facteurs de virulence est encore incertain. Il semble légitime d'admettre que toutes les souches sont capables de coloniser l'intestin grâce à leur affinité pour le mucus. Les souches pathogènes adhèrent aux entérocytes, mais les événements ultérieurs doivent être diffé- 


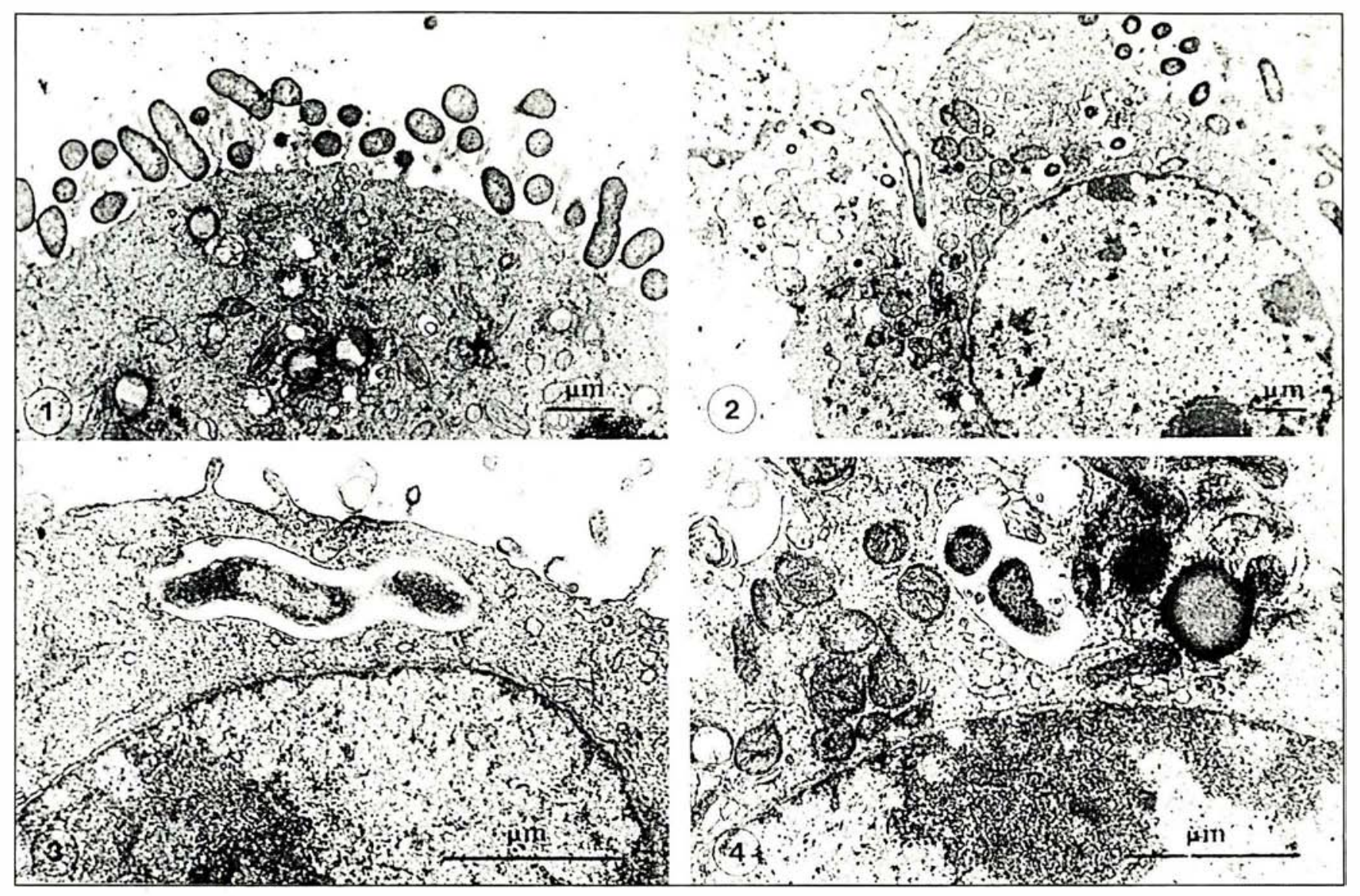

Figure 3. Cellules Hela infectées avec C. jejuni. Sections ultrafines observées en microscopie électronique. 1 = adhérence des bactéries à la membrane plasmique ; 2 = internalisation d'une cellule bactérienne ; $3-4=$ cellules bactériennes dans des vacuoles d'endocytose.

rents selon la nature des autres facteurs de virulence. Cela implique l'existence, dans le groupe des Campylobacter entéropathogènes, de plusieurs types pathogènes définis en fonction de l'expression de propriétés d'adhérence, d'entérotoxicité, de cytotoxicité ou d'invasivité. Il est de plus probable que l'expression clinique très polymorphe est influencée par les circonstances de l'infection et la réponse de l'hôte. On a ainsi avancé que les formes bénignes survenant dans la prime enfance dans les pays en voie de développement pourraient conférer une immunité aux sujets de ces pays alors que dans les pays développés, l'infection par les mêmes types (pathotypes), survenant plus tard chez un sujet non immun, provoquerait une maladie plus grave.

\section{Réponse de l'hôte à l'infection}

Un certain nombre de processus non spécifiques s'opposent à la colonisation de l'intestin par les Campylobacter. L'acidité gastrique détruit une grande partie de l'inoculum et pour que les Campylobacter franchissent l'estomac, il faut que cet inoculum soit élevé et soit administré avec des anti-acides (bicarbonate) ou à un moment où l'acidité gastrique est tamponnée par des aliments, par exemple. La diminution du péristaltisme augmente la sévérité de l'infection. Les Campylobacter sont très sensibles à l'activité bactéricide du plasma, ce qui explique la fugacité de la bactériémie qui s'observe dans les stades précoces de l'infection. Certaines souches sont plus résistantes, mais surtout certains sujets aux défenses amoindries peuvent présenter de véritables septicémies au cours des entérites à Campylobacter.

Les entérites à Campylobacter induisent une réponse anticorps à $\operatorname{Ig} \mathrm{A}, \operatorname{IgG}$ et IgM. Les taux d'anticorps restent élevés dans le sérum pendant les semaines qui suivent l'infection. Les anticorps protecteurs sont dirigés contre les antigènes bactériens exposés à la surface et notamment la flagelline, les protéines d'adhérence de 26-30 kDa et le LPS. Ces anticorps sont présents chez les convalescents mais aussi chez de nombreux sujets sans antécédents connus ; ce qui suggère qu'il existe de nombreuses infections inapparentes. Des IgA sécrétoires spécifiques ont également été mis en évidence. L'immunité est transmissible par voie transplacentaire et par le lait. La prévalence des anticorps augmente avec l'âge en même temps que celle des infections diminue. Enfin la prévalence de l'entérite à Campylobacter ne semble pas augmentée chez les malades atteints de SIDA. 


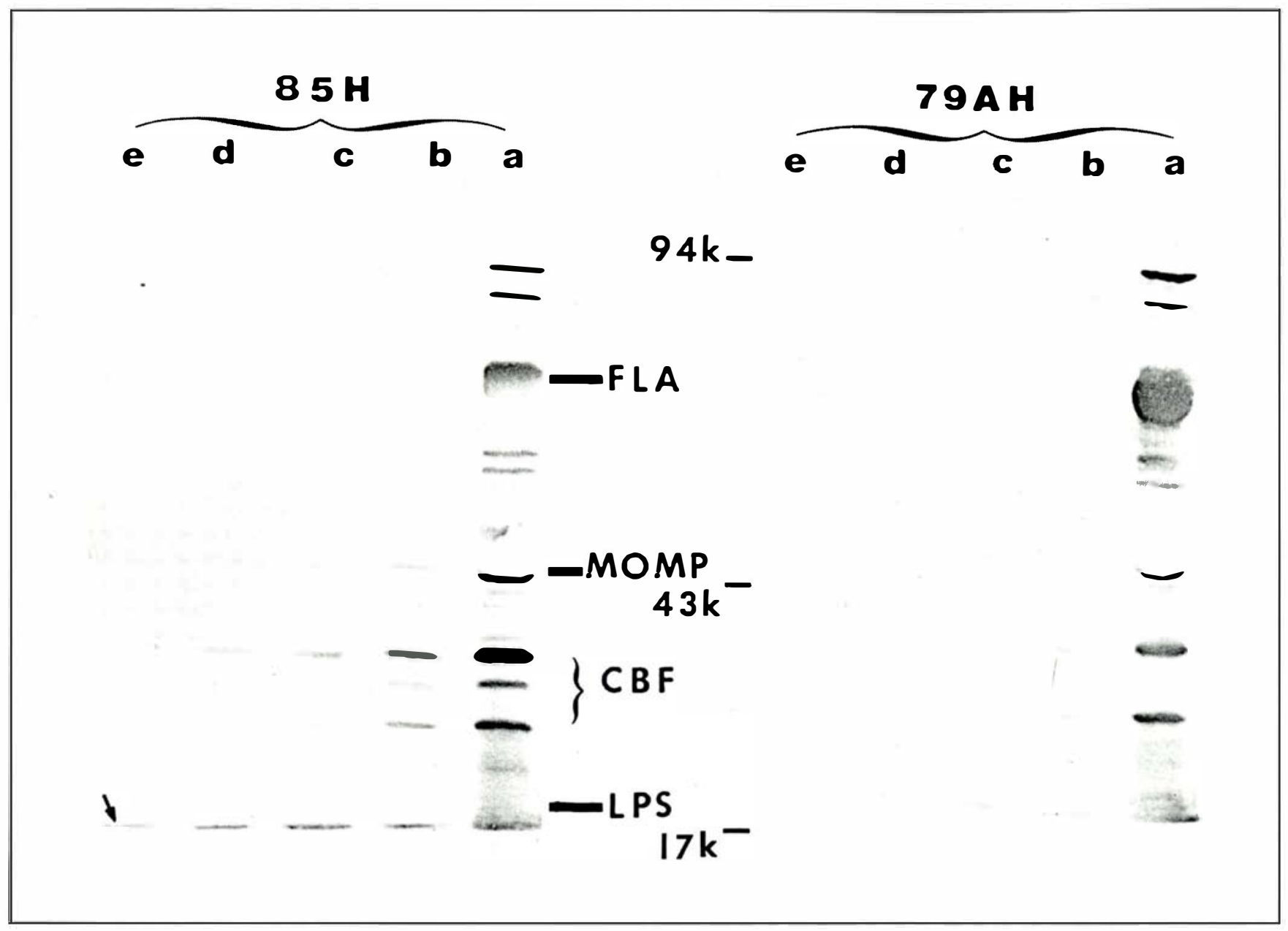

Figure 4. Adhérence de membranes externes bactériennes isolées sur des cultures de cellules HeLa. Colonnes a : profils antigéniques des membranes externes de deux souches de Campylobacter (85H et 79 AH); colonnes b à $e$ : profils antigéniques de dilutions de raison $1 / 2$, de lysat cellulaire ayant fixé les composants adhérents des membranes externes bactériennes. Certains antigènes de l'une des souches (CBF) se fixent préférentiellement aux cellules $; 85 \mathrm{H}=$ souche très adhérente; $79 \mathrm{AH}=$ souche peu adhérente. Chaque souche est révélée par un sérum homologue préalablement absorbé sur des cellules HeLa et qui ne reconnaît que les antigènes bactériens. FLA : flagelline; MOMP : major outer membrane protein; CBF : cellular binding factor; LPS : lipopolysaccharide.

\section{Infections gastriques à Helicobacter (Campylobacter) pylori}

Ce n'est qu'en 1983 que les bactéries spiralées, qui avaient été observées depuis déjà une cinquantaine d'années sur la muqueuse gastrique de patients souffrant de gastrite active, ont pu être cultivées. Ces bactéries, tout d'abord rattachées au genre Campylobacter et dénommées C. pyloridis puis $C$. pylori, ont fait récemment l'objet d'études taxonomiques qui ont montré qu'elles représentaient un genre nouveau comprenant des espèces isolées strictement - soit chez l'homme, soit chez l'ani-
Le rôle de $H$. pylori dans les maladies inflammatoires gastriques est très débattu [15-17]. De nombreuses études ont démontré une forte corrélation entre la présence de $H$. pylori dans l'estomac et l'existence soit d'une gastrite de type B (voir plus loin), soit d'un ulcère peptique. Ainsi, cette bactérie qui n'est retrouvée que dans l'estomac humain ou sur des métaplasies gastriques du duodénum, pourrait être la responsable ou un cofacteur des maladies inflammatoires gastriques. Mais elle pourrait également n'être qu'un commensal opportuniste qui prolifère préférentiellement sur une muqueuse lésée. C'est en tout cas un excellent marqueur des maladies gastriques auxquelles elle est associée.

\section{Caractères bactériologiques de Helicobacter pylori}

$H$. pylori est une bactérie à Gram négatif spiralée, incurvée ou en forme de " $\mathrm{U}$ " ou de " $\mathrm{O}$ "(Donuts shape), mobile par 4 à 6 flagelles polaires engainés. Cette bactérie pousse en 3 à 5 jours surtout en milieu gélosé additionné de sang, de sérum ou d'amidon et sous atmosphère microaérophile. Des formes coccoïdes apparaissent dans les vieilles cultures et seraient pour certains, des formes de dégénérescencn, pour d'autres, des 
formes de résistance. Le capital enzymatique de $H$. pylori est important, il possède une catalase, une oxydase, des amidases, des peptidases, des phosphatases et surtout une uréase extracellulaire similaire à celles d'autres bactéries mais en quantité extrêmement importante. Cette enzyme, présente dans le matériel bactérien exposé en surface, joue probablement un rôle important dans la colonisation de la muqueuse, le pouvoir pathogène et peut-être le métabolisme de la bactérie [18].

\section{Les maladies}

\section{inflammatoires gastriques}

Les gastrites chroniques sont des entités cliniques très polymorphes, définies et classées différemment selon les auteurs. L'apparition de la microbiologie dans la pathologie gastrique aura au moins eu l'avantage d'obliger gastroentérologues, histologistes et microbiologistes à confronter leurs points de vue pour engendrer des définitions et une classification cohérente de ces maladies.

Un premier type de gastrite intéresse le fundus et s'accompagne d'une destruction des cellules pariétales (sécrétant l'acide chlorydrique) et de la présence fréquente de métaplasies intestinales. Ces gastrites sont souvent associées à une anémie pernicieuse et à des processus autoimmuns mais ne sont pas liées à la présence de $H$. pylori. On les nomme gastrites de type A ou gastrites chroniques métaplasiques atrophiques. Le second type de gastrite concerne surtout la région antrale et touche les cellules productrices de mucus. Elles s'accompagnent fréquemment de métaplasies gastriques dans le duodénum et sont corrélées à la présence de $H$. pylori. Ces gastrites sont dites de type $\mathrm{B}$ ou antrales, et on les dit actives s'il existe un infiltrat de polynucléaires dans la muqueuse. Les deux types de gastrites - fundique et antrale - s'accompagnent de la présence de cellules mononucléées infiltrant la muqueuse. Les ulcères peptiques sont des pertes de substance de la muqueuse antrale ou duodénale qui s'accompagnent presque toujours de gastrites et sont corrélés à la présence de $H$. pylori. Les dyspepsies non ulcéreuses réunissent $m / s n^{\circ} 2$, vol. 7, février 91 certains symptômes des ulcères (douleurs épigastriques, nausées, vomissements, ballonnements) mais sans ulcérations visibles. Ces dyspepsies sont également associées à la présence de $H$. pylori.

Jusqu'à la découverte de $H$. pylori, l'étiopathogénie de toutes ces maladies étaient mal comprise et on s'accordait seulement sur des circonstances ou facteurs favorisants comme le tabac, l'alcool, des facteurs nutritionels, le stress ou le mode de vie. Même si sa responsabilité directe n'est pas encore admise par tous, le rôle de cofacteur étiologique de $H$. pylori est de plus en plus probable et de nombreux arguments épidémiologiques expérimentaux, immunologiques et thérapeutiques plaident pour cette hypothèse [19].

\section{Pouvoir pathogène de H. pylori}

Malgré les différences de définition des diverses formes de gastrites, on peut globalement dire que la présence de $H$. pylori dans l'estomac s'accompagne presque toujours d'un processus inflammatoire qui reste asymptomatique ou se traduit par une gastrite le plus souvent antrale, accompagnée ou non de lésions ulcéreuses gastroduodénales, alors que les sujets indemnes de toutes lésions inflammatoires ou ulcéreuses ou les sujets atteints de gastrites médicamenteuses ou de gastrites autoimmunes n'hébergent pas $H$. pylori. Sur la muqueuse, les bactéries sont surtout localisées au niveau des jonctions intercellulaires qui apparaissent altérées. $H$. pylori n'a jamais été vu en situation intracellulaire. Les porteurs de $H$. pylori synthétisent des anticorps spécifiques qui sont retrouvés dans le sérum et sur la muqueuse elle-même. L'éradication thérapeutique des bactéries par les sels de bismuth ou/et des antibiotiques s'accompagne d'une guérison de l'inflammation et les rechutes s'accompagnent de la réapparition de $H$. pylori. Enfin les infections expérimentales de deux volontaires humains ont abouti à l'apparition de gastrites cliniques et histologiques avec implantation des bactéries qui n'étaient plus retrouvées après la guérison.

L'ensemble de ces données suggère donc une responsabilité directe de $H$. pylori dans les gastrites et les ulcères peptiques gastro-duodénaux. Cependant, chez des patients antérieurement ulcéreux et vagotomisés, l'infection par $H$. pylori ne s'accompagne d'une rechute de l'ulcère que dans $17 \%$ des cas. Il semble donc que d'autres facteurs soient nécessaires au développement ou à la rechute d'un ulcère. La tendance actuelle est de considérer que les maladies inflammatoires et les ulcères gastriques sont la conséquence de causes multiples agissant ensemble ou séquentiellement et conduisant d'une inflammation asymptomatique à une gastrite clinique puis à un ulcère qui serait le stade évolutif ultime. L'infection par $H$. pylori constituerait l'une des étapes de ce processus, peut-être l'une des premières. Le problème est de savoir laquelle ou lesquelles de ces étapes il faut bloquer par un traitement approprié pour empêcher le développement de ce processus et le faire régresser sans risque de rechute. C'est actuellement l'une des questions les plus débattues et il ne semble pas que l'élimination de $H$. pylori par les traitements actuellement tentés réalisent ces objectifs.

\section{Épidémiologie}

La prévalence du portage de $H$. pylori de même que la présence d'anticorps sériques augmentent avec l'âge pour atteindre $50 \%$ chez les sujets de plus de 60 ans. Les porteurs sont souvent peu ou pas symptomatiques, mais les études histologiques montrent l'existence constante d'une gastrite qui est absente chez les non-porteurs. Ainsi on tend à admettre que cette bactérie est un pathogène causant fréquemment des infections asymptomatiques qui ne deviennent symptomatiques que chez certains sujets ou en présence d'autres facteurs de pathogénicité. Actuellement, cette bactérie n'a été retrouvée que dans l'estomac de l'homme (quelques animaux hébergent des bactéries voisines), bien qu'elle ait été recherchée dans de nombreux autres sites anatomiques dans l'environnement et chez de nombreux animaux. Il est possible cependant que l'utilisation de méthodes très sensibles utilisant des sondes nucléiques (PCR) puissent l'identifier 


\section{RÉFÉRENCES}

13. Fauchìre JL, Rosenau A, Veron $M$, Moyen EN, Richard S, Pfister A. Association with HeLa cells of Campylobacter jejuni and Campylobacter coli isolated from human feces. Infect Immun 1986; 54 : 283-7.

14. Fauchìre JL, Kervella M, Rosenau A Mohanna K, Veron M. Adhesion to HeLa cells of Campylobacter jejuni and $C$. coli outer membrane components. Res Microbiol 1989 ; 140 : 379-92.

15. Fauchìre JL, Bonneville F, DroyLefaix MT. L'ulcìre de l'estomac, une maladic bactérienne? La Recherche 1987 ; $18: 522-4$

16. Blaser MJ. Gastric Campylobacter like organisms, gastritis and peptic ulcer disease. (iastroenterology 1987; $93: 371-83$

17. Buck GE. Campylobacter pylori and gastroduodenal disease. Clin Microb Rev 1990 ; $3: 1-12$.

18. Goodwin CS, Armstrong JA. Microbiological aspects of Helicobacter pylori (Campylobacter pylori). Eur J Microbiol Infect Dis $1990 ; 9: 1-13$.

19. Blaser MJ. Campylobacter pylori in Gastritis and Peptic Ulcer Disease. New YorkTokyo : Igaku-Shoin, 1989.

20. Fauchère JL, Rosenau A. Interactions entre les Campylobacter pathogènes pour l'homme et les muqueuses digestives. Med Mal In fect $1989 ; 19: 61-67$.

21. Fauchìre JL, Rosenau A, Bonneville F. Virulence factors of Campylobacter pylori. Gas troenterol Clin Biol 1989; 13 : 59B-64B.

22. Evans DG, Evans DJ, Moulds JJ, Graham DY. N-Acetyl-neuraminyl-lactosebinding fibrillar hemagglutinin of Campylobacter pylori : a putative colonization factor antigen. Infect Immun 1988 ; 56 : 2896-906.

23. Fauchìre JL, Blaser MJ. Adherence of Helicobacter pylori and superficial components to HeLa cell membranes. Microbiol Pathogenesis 1990 ; 9 (sous presse).

24. Labigne-Roussel A, Courcoux P, Tomkins L. Gene disruption and replacement as a seasible approach for mutagenesis of Campylobacter jejuni. I Bacteriol 1988; 170 . dans des sites comme l'intestin ou la bouche. Le mode de transmission le plus probable est la transmission orale interhumaine, mais cela n'a pas été formellement démontré. Des épidémies de gastrites hypochlorhydriques ont été attribuées à $H$. pylori chez des sujets qui avaient été soumis à des endoscopies digestives. On pense que, dans ces cas, la transmission par le matériel endoscopique est probable. Une fois l'estomac colonisé, la bactérie reste en place pendant au moins 4 ans, mais, sur la base d'arguments sérologiques, on peut dire qu'elle reste probablement plus longtemps et peut-être le reste de la vie.

\section{Facteurs bactériens de virulence}

En dehors des infections de volontaires humains, les infections expérimentales par $H$. pylori ont donné jusqu'à présent des résultats décevants. Les tentatives pour implanter $H$. pylori chez des animaux courants de laboratoire ont échoué. On a pu coloniser l'estomac du porcelet gnotoxénique ou de certains singes et voir apparaître une inflammation de la muqueuse, mais les gastrites ou les ulcères peptiques humains n'ont pu être reproduits. La compréhension des mécanismes par lesquels $H$. pylori colonise l'estomac et participe aux maladies inflammatoires gastriques est donc actuellement fondée sur des données obtenues in vitro $[15,17,20$, 21].

L'implantation de $H$. pylori sur la muqueuse suppose qu'il puisse y accéder malgré la barrière constituée par le mucus visqueux et malgré l'acidité gastrique qui tue la plupart des autres bactéries. On a démontré que la grande mobilité et la morphologie spiralée de $H$. pylori lui permettent de traverser le mucus beaucoup mieux que les autres germes. $H$. pylori est aussi sensible que les autres bactéries à l'acidité gastrique, cependant, on a démontré qu'en présence d'urée, il restait viable dans un milieu à pH 2. Cette résistance est due à sa puissante uréase qui, hydrolysant l'urée, libère de l'ammoniac tamponnant l'acidité du milieu. Il est probable que c'est ainsi que $H$. pylori parvient à s'implanter de façon durable dans l'estomac.
L'uréase de $H$. pylori est comparable à celles connues chez d'autres bactéries ou chez certains végétaux. Cependant les quantités synthétisées et excrétées par $H$. pylori sont considérables. Cette enzyme a été très étudiée, elle est associée à deux peptides de 62 et $30 \mathrm{kDa}$ et contrôlée génétiquement par 3 gènes chromosomiques. A l'état natif, elle serait formée d'un complexe de $600 \mathrm{kDa}$. Elle intervient probablement à de nombreux niveaux comme facteur de colonisation et enzyme métabolique pour la survie de $H$. pylori dans son écosystème naturel.

L'observation des coupes biopsiques en microscopie électronique montre que les bactéries sont étroitement adhérentes aux membranes des cellules de la muqueuse (figure 5). In vitro, on a mis en évidence plusieurs composés bactériens pouvant jouer le rôle de facteurs d'adhérence. Plusieurs hémagglutinines, définies notamment par l'origine des hématies qu'elles agglutinent, ont été identifiées et parfois purifiées [22]. Certains récepteurs cellulaires auxquels se fixent ces hémagglutinines sont connus (N-acétyl-neuraminyllactose) ; cependant, ces récepteurs sont retrouvés sur la plupart des cellules épithéliales quelle que soit leur origine, et même sur certaines protéines sériques. Si ces hémagglutinines jouent un rôle dans l'adhérence de $H$. pylori aux cellules gastriques, il est donc peu probable qu'elles expliquent sa spécificité pour l'estomac par rapport aux autres tissus. $H$. pylori adhère fortement in vitro aux cellules épithéliales cultivées (figure 6, p. 150). Grâce à des microméthodes récepteur/ligand, nous avons pu étudier l'adhérence de divers constituants de la bactérie sur divers constituants des cellules cibles [23]. Après extraction de l'abondant matériel bactérien superficiel qui entoure les cellules bactériennes, les propriétés d'adhérence de ces bactéries aux membranes des cellules épithéliales diminuent de $70 \%$. Les extraits bactériens sont riches en matériel adhérent. La séparation chromatographique en gel d'exclusion des constituants de ce matériel superficiel démontre que les activités d'adhérence et uréasique sont copurifiées dans les mêmes fractions contenant 

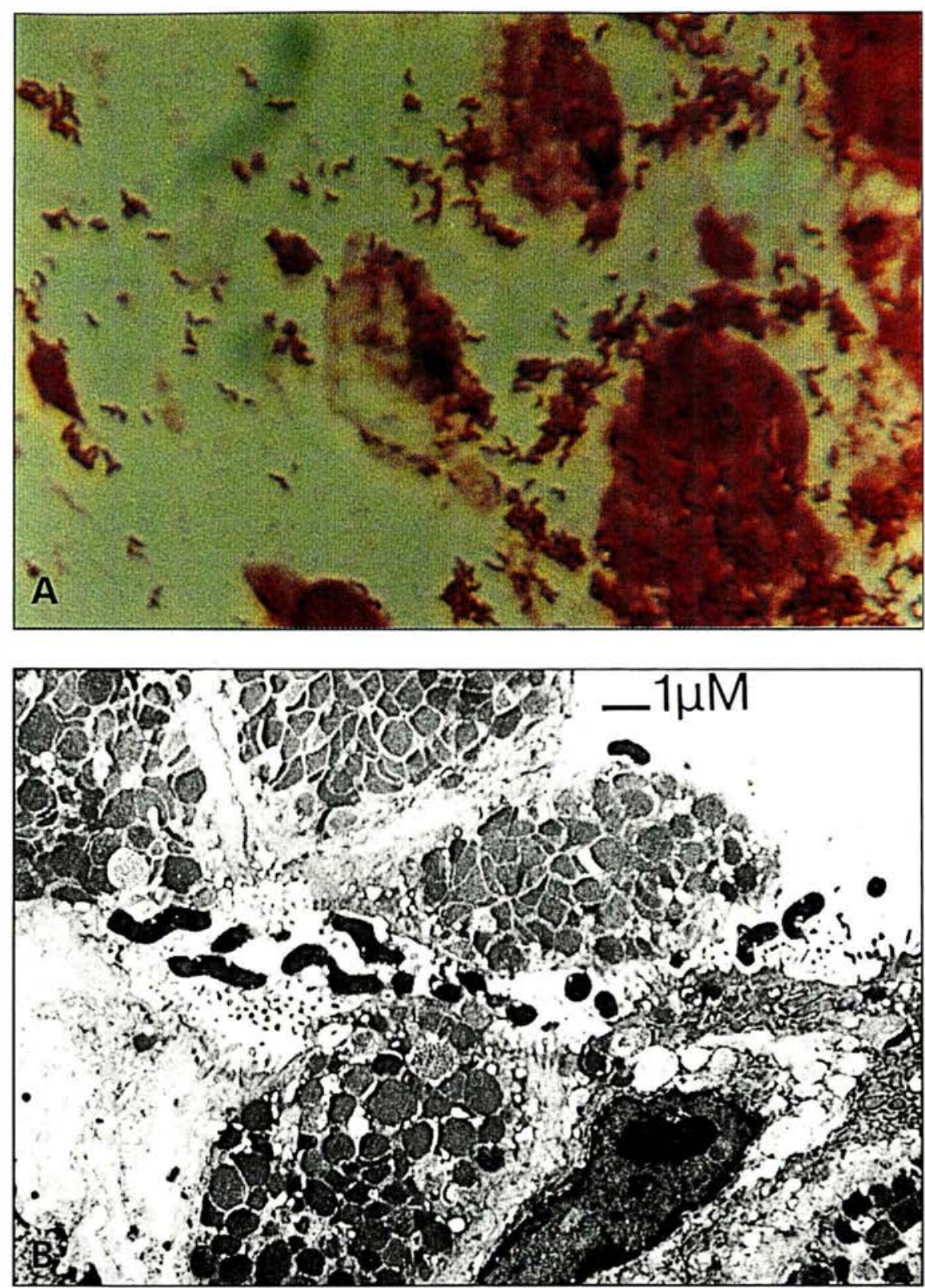

Figure 5. Helicobacter pylori dans une biopsie gastrique. $A$ : coloration de Gram, microscopie optique ; 8 : microscopie électronique.

des antigènes protéiques de 60,30 et $15 \mathrm{kDa}$ (figure 7, p. 151) [23]. A l'état natif, ces fractions protéiques semblent exister sous la forme d'un complexe de haut poids moléculaire. Des anticorps spécifiques de chaque sousunité de ce complexe ont permis d'identifier la sous-unité adhérente à un antigène de poids moléculaire voisin de $60 \mathrm{kDa}$. Cet antigène est aussi l'un des composants les plus immunogènes chez les sujets infectés, ce
H. pylori est entouré d'un abondant matériel protéique probablement sécrété par la bactérie. Ce matériel possède une activité uréasique intense qui assure à la cellule bactérienne une protection vis-à-vis de l'acidité gastrique. Ce matériel est également capable de se fixer sur les cellules de l'épithélium gastrique et participe sans doute ainsi à l'adhérence des bactéries à la muqueuse. La muqueuse revêtue du matériel bactérien adhérent subit probablement des dommages dus à la production locale de grandes quantités d'ammoniac. L'existence de cet antigène bactérien intimement associé aux cellules induit probablement une réaction inflammatoire et un recrutement cellulaire qui doivent participer à la genèse des lésions. Il se pourrait aussi que ces antigènes présents en grande abondance et sécrétés en permanence par les bactéries saturent les anticorps produits localement par l'hôte et les empêchent ainsi de se fixer aux cellules bactériennes, ce qui induirait une sorte de tolérance de la muqueuse aux bactéries et pourrait en partie expliquer leur persistance en dépit d'une réponse immunitaire locale et générale. Par ailleurs, une activité cytotoxique vacuolisante a été mise en évidence in vitro, mais son implication dans le processus physiopathologique des gastrites et des ulcères est discutée puisque toutes les souches ne l'expriment pas et qu'elle n'est pas cytolétale.

Certains ont tentés de réconcilier les concepts physiopathologiques traditionnels des gastrites et des ulcères avec l'intervention de $H$. pylori. Les ulcères duodénaux associés à $H$. pylori surviennent chez des patients hyperchlorhydriques qui développent des métaplasies gastriques dans leur duodénum. Ces métaplasies seraient préférentiellement colonisées par les $H$. pylori venant de l'antre et les ulcères apparaîtraient préférentiellement au niveau de ces métaplasies, ce qui est de fait observé à l'histologie. L'hyperchlorhydrie serait due à une hyperproduction de gastrine en réponse à l'augmentation du $\mathrm{pH}$ au niveau de la muqueuse à la suite de la libération d'ammoniac. Il reste également à expliquer l'apparente sélectivité de $H$. pylori pour le tissu gastrique. Cela pourrait être du à des 


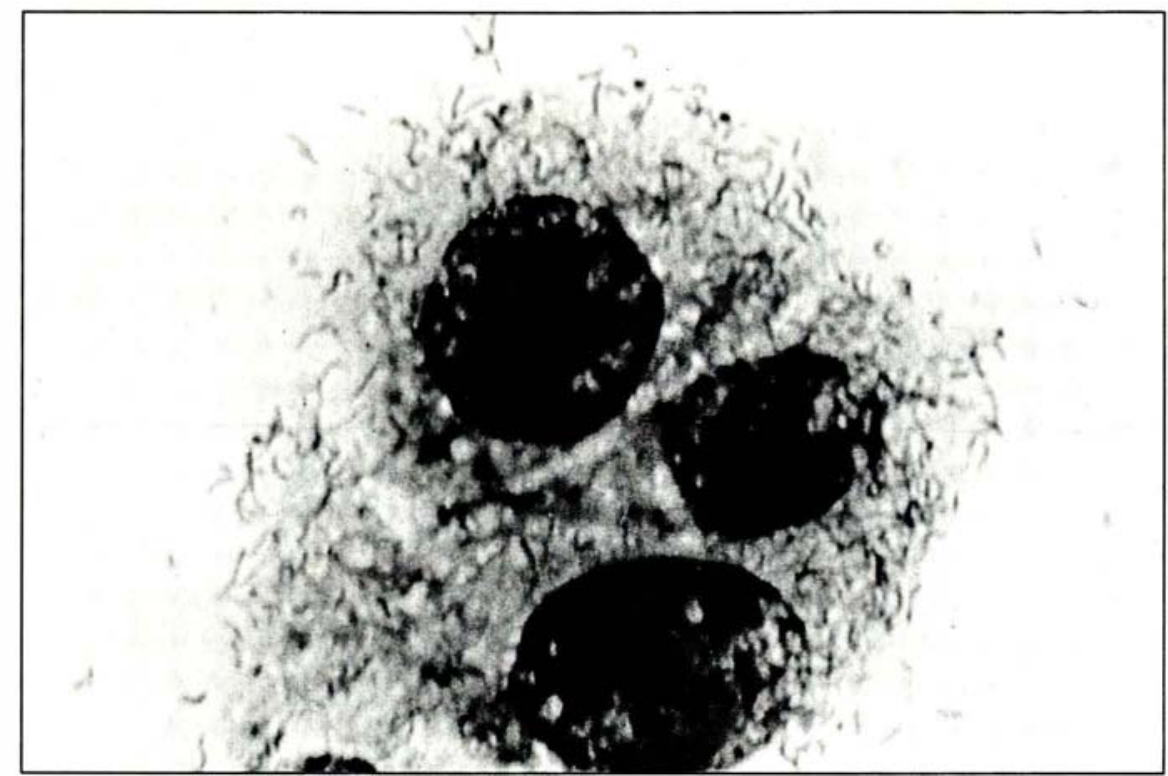

Figure 6. Adhérence de H. pylori sur des cellules HeLa en culture (coloration de Giemsa). Les bactéries sont incubées 60 min avec une monocouche de cellules HeLa. Après six lavages pour éliminer les bactéries non adhérentes, les préparations sont fixées, colorées et observées au microscope.

récepteurs d'adhérence bactérienne exclusivement présents à ce niveau ou, plus probablement, à un effet sélectif qui empêcherait les bactéries moins bien adaptées de s'implanter dans l'environnement gastrique.

Chacune de ces hypothèses physiopathologiques nécessite d'être étayée par d'autres données expérimentales, mais elles sont actuellement des bases de raisonnement précieuses pour explorer les mécanismes de ces maladies, pour lesquelles n'existent pas de modèles animaux simples et, jusqu'à ces derniers mois [24], d'outils génétiques classiquement utilisés pour comprendre la physiopathologie d'autres infections.

\section{Diagnostic biologique de Helicobacter pylori}

Pour dépister les porteurs de Helicobacter pylori, on peut recourir à des méthodes bactériologiques, anatomopathologiques, biophysiques ou sérologiques. Au cours d'une fibroscopie gastro-duodénale, on prélèvera plusieurs biopsies à proximité de zones lésées de la muqueuse ou, à défaut, dans l'antre où sont préférentiellement localisés les Helicobacter, et éventuellement dans le fundus, le duodé-

l'emploi de la benzocaïne - qui peut inhiber la croissance de $H$. pylori et qui pourra être remplacée par la lidocaïne. L'examen minutieux d'un frottis, d'une coupe ou d'une empreinte biopsique après simple coloration de Gram permet de repérer les Helicobacter par leur morphologie caractéristique. D'autres colorations, Giemsa modifié, acridine orange, imprégnation argentique de Warthin-Starry, qui épaissit les corps bactériens, ou immunofluorescence directe à l'aide d'anticorps monoclonaux peuvent faciliter leur mise en évidence. Ces techniques rapides manquent de spécificité et ne renseignent pas sur la viabilité des bactéries. Par ailleurs, on peut détecter directement l'activité uréasique dans les biopsies. Cette technique donne des résultats semi-quantitatifs en moins d'une heure avec une spécificité de $74 \%$ et une sensibilité de 66 à $83 \%$ par rapport à la culture. L'isolement de $H$. pylori par culture des biopsies reste donc la méthode de référence. Les biopsies ne peuvent se conserver que quelques heures dans un milieu de transport humide. Les milieux de culture doivent renfermer soit du sérum, soit du sang frais, lysé ou cuit, soit du charbon ou de l'amidon de maïs et sont éventuellement rendus sélectifs par l'addition d'antibiotiques visant à éliminer les contaminants. Ils doivent être incubés pendant 3 à 7 jours à $37^{\circ} \mathrm{C}$ en atmosphère microaérophile ou enrichie de $10 \%$ de $\mathrm{CO}_{2}$ qui peut être renouvelée après 48 heures pour obtenir un meilleur rendement de culture. Les colonies sont alors facilement identifiées d'après leur aspect, l'examen microscopique, la présence d'une oxydase, d'une catalase et d'une uréase très puissantes que l'on peut mettre en évidence en quelques minutes.

Le. diagnostic peut également être pośé sans pratiquer d'examen endoscopique. La mise en évidence d'une activité uréasique peut se faire après ingestion d'urée marquée au carbone radioactif et dosage dans l'air expiré du $\mathrm{CO}_{2}$ marqué provenant de la dégradation de l'urée (Breath test). Ces méthodes sont sensibles et très spécifiques et donnent des résultats semiquantitatifs sur le degré d'infection de tout l'estomac. Elles permettent la surveillance des traitements sans répéter les fibroscopies et la méthode au ${ }^{13} \mathrm{C}$ est particulièrement adaptée aux enfants. Enfin, les techniques sérologiques permettent un diagnostic avec une bonne sensibilité par rapport à celles de diagnostic direct. La technique ELISA est la plus employée. Cependant, ces sérologies sont encore mal standardisées et les antigènes utilisés varient d'un laboratoire à l'autre.

L'étude de la sensibilité in vitro de $H$. pylori aux antibactériens a montré l'excellente activité de la plupart des antibiotiques à l'exception de la vancomycine, des sulfamides, du triméthoprime et de la cefsulodine, ainsi que l'activité modérée des sels de bismuth et de l'oméprazole. Ces données ont incité de nombreuses équipes à associer au traitement classique des gastrites et des ulcères peptiques par anti- $\mathrm{H}_{2}$, des antibiotiques et des sels de bismuth. Alors que la rémission clinique qui suit un traitement par cimétidine ou ranitidine seules ne permet pas l'éradication des bactéries et est très généralement suivie de rechute, les traitements associant deux ou trois molécules à activité antibactérienne peuvent éradiquer $H$. pylori. Ces traitements permettent des rémissions plus longues, 


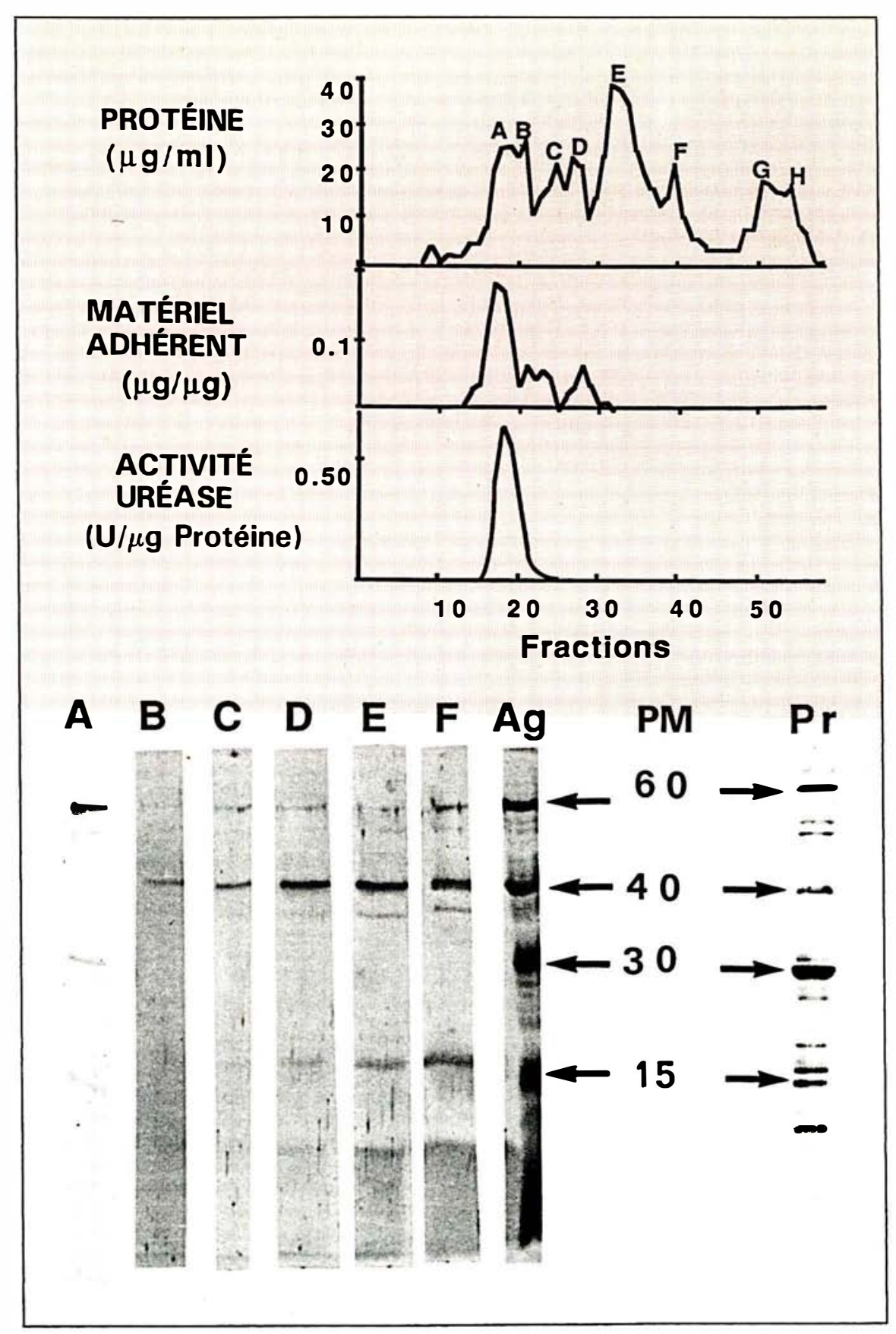

Figure 7. Séparation chromatographique des antigènes d'adhérence de H. pylori. Un extrait aqueux d'une souche de $\mathrm{H}$. pylori adhérente et séparée par chromatographie en gel d'exclusion. Chaque fraction est examinée pour ses activités uréasiques et d'adhérence et analysée par Western Blot contre un sérum anti-H. pylori. L'uréase et les antigènes d'adhérence sont copurifiés dans les fractions précoces qui contiennent des antigènes de 60 à 30 et $14 \mathrm{kDa}$. Ag: révélation des protéines non fractionnées par l'anticorps; $\mathrm{Pr}$ : révélation des protéines fractionnées par une coloration non spécifique. et les rechutes - qui sont plus rares - sont généralement liées à la réapparition des germes. Les antibiotiques les plus actifs sont les fluoroquinolones, les furanes et les imidazoles qui peuvent se concentrer dans la muqueuse gastro-duodénale.

$H$. pylori peut développer rapidement des résistances contre les agents antibactériens, soit in vitro par des expériences de sélection, soit in vivo en cours de traitement. Aucune résistance n'a encore été décrite aux $\beta$ lactamines, aux tétracyclines, au chloramphénicol ni aux sels de bismuth. En revanche, des résistances aux quinolones, aux imidazoles, à la rifampicine, à l'érythromycine et à la tobramycine, principalement par des phénomènes de mutation, ont été déjà rapportées. La résistance aux imidazoles touche déjà $40 \%$ des souches en France et est particulièrement préoccupante. Les mécanismes de ces résistances sont encore mal connus. L'utilisation de plusieurs antibiotiques associés entre eux ou à un sel de bismuth permet de limiter l'émergence de souches résistantes.

En France, où les médicaments à base de bismuth ne sont pas commercialisés, les traitements les plus courants associent un anti- $\mathrm{H}_{2}$ ou l'oméprazole à deux antibiotiques tels que le métronidazole ou le tinidazole, l'amoxicilline ou une tétracycline

Remerciements

Le travail développé dans notre laboratoire sur la physiopathologie des infections à Campylobacter et Helicobacter a bénéficié, depuis 1983, des soutiens: de l'université Paris V, de l'Inserm, de la Fondation Philippe, des Instituts IPSEN et H.-Beaufour. Les chercheurs qui ont collaboré à ces travaux sont, par ordre alphabétique : F. Bonneville, M. Boulot-Tolle, M.T. Droy, J.-L. Fauchère, M. Kervella, K. Mohanna, E.-N. Moyen, A. Rosenau, M. Véron. Nous avons bénéficié des conseils de $\mathrm{Ph}$. Sansonetti, P. Berche, A. LabigneRoussel, M.-J. Blaser, G. Perez-Perez. Ces travaux ont été réalisés dans les laboratoires de bactériologie de la faculté de médecine Necker - Enfants - Malades, Paris et du VA Medical Center, University of Colorado Denver Co, USA 


\section{Summary}

Campylobacter and Helicobacter in gastro-intestinal pathology

Campylobacter and Helicobacter are microaerobic Gram negative bacteria well adapted to the digestive tract. These bacteria are respectively associated with enteritis and gastric inflammatory diseases. The Campylobacter enteritis are worldwide and clinicaly polymorph. Their prevalence is close from those of gastro-intestinal salmonellosis. Bacteriological diagnosis is based on isolation of Campylobacter from stools. Campylobacter are relatively sensitive to antibiotics but acquired resistances are now raising. The pathophysiology of Campylobacter enteritis is, up to now, poorly understood. Both adaptation to mucus and colonization factors are probably involved in intestinal colonization. The clinical presentation of enteritis may be determined by presence of toxins as well as by the host response.

The presence of $H$. pylori on gastric mucosa has been correlated with inflammation of mucosa which may be asymptomatic or may be clinically associated with antral type B gastritis or peptic ulcer disease. $H$. pylori is a motile Gram negative microaerobic spiral. This bacteria is detected on the gastric mucosa by cultivation from gastric biopsies, by detection of its strong urease or by serological methods. H. pylori is sensitive to numerous antibiotics and to bismuth salts. The role of $H$. pylori in gastric inflammatory diseases is still controversed. These bacteria are particularly well adapted to the gastric milieu whose colonization involves urease and several putative colonization factors. The role of $H$. pylori in creation of mucosal damages is up to now poorly understood.

\section{TIRÉS A PART}

